\title{
Analysis of Single Nucleotide Polymorphisms in the QTLS Associated with Tick Resistance/Susceptibility in the Native Vechur and Cross red Cattle of Kerala State
}

\author{
Bhagyashree Kamble Mukhund ${ }^{1}$, C. N. Dinesh ${ }^{1}$, P. M. Rojan, Reghu Ravindran², \\ K. A. Bindu ${ }^{3}$, V. N. Muhasin Asaf ${ }^{2}$, P. R. Sreeshma ${ }^{2}$ and T. Deepna ${ }^{2}$ \\ ${ }^{1}$ Department of Animal Genetics and Breeding, ${ }^{2}$ Department of Veterinary Parasitology, \\ College of Veterinary and Animal Sciences, Pookode, India \\ ${ }^{3}$ Department of Animal Genetics and Breeding, College of Veterinary and Animal Sciences, \\ Mannuthy, Kerala Veterinary and Animal Sciences University, India \\ *Corresponding author
}

\section{A B S T R A C T}

Tick infestation is a major reason for economic loss in livestock production in the tropical countries. However, animals show variation in resistance and susceptibility to tick infestation. Bos indicus breeds were reported to be more resistant to tick infestation than

Keywords

Ticks, tick resistance, QTL, SNP, Vechur, crossbred cattle, Kerala

\section{Article Info}

Accepted:

20 August 2020

Available Online:

10 September 2020 Bos taurus cattle. The present study aimed to identify polymorphisms in four quantitative trait loci (QTLs) that were stated to be associated with resistance/susceptibility to tick infestation, in a population comprising native Vechur breed $(n=45)$ and crossbred cattle $(n=74)$ of the Kerala Veterinary and Animal Sciences University farms. The QTLs were selected from the Animal QTL Database (https://www.animalgenome.org/cgibin/QTLdb/index). The single nucleotide polymorphisms (SNP) and the QTLs (in parenthesis) used in this study were: rs41661020 (\#101148), rs43708490 (\#135798), rs41577070 (\#135800) and rs29009970 (\#135801). Blood samples were collected from the animals, isolated the DNA and used for genotyping and polymorphism study by Polymerase Chain Reaction-Restriction Fragment Length Polymorphism and confirmed by sequencing. The results revealed polymorphic pattern for the SNPs rs41577070, rs41664020, and SNP rs43708490 in both Vechur and cross-bred populations. The SNP rs29009970 was monomorphic in the crossbred cattle, whereas, dimorphic in Vechur. Genotyping was done by direct counting and the allelic and genotypic frequencies were estimated by POPGENE 1.32. Chi-square test revealed that crossbreds and Vechur were in Hardy-Weinberg equilibrium for SNPs rs41577070, rs41664020, and rs43708490, whereas, the SNP rs29009970 showed a significant departure from the equilibrium.

\section{Introduction}

More than $80 \%$ of the cattle population in the world are affected by ticks and tick-borne infections (Food and Agriculture Organisation, 1984) which cause huge economic loss in cattle rearing in tropical and sub-tropical countries including India (Ghosh et al., 2007). The world economy suffers an estimated loss of US\$20 to US\$30 billion per annum due to ticks and tick-borne infections (TTBDs) (Lew-Tabor and Valle, 2016). The 
estimated loss due to TTBDs for the Indian economy is US\$ 498.7 million per annum (Minjauw and McLeod, 2003).

Even though, acaricides form the mainstay of tick control methods, the development of acaricide resistant ticks (Li et al., 2005), high price of acaricides and the likelihood of presence of its residues in the animal products made the use of chemical acaricides less attractive (Castro-Janer et al., 2010).Hence, the researchers introduced the idea of using resistant breeds as an alternate strategy for control of tick burden in cattle.In general, Bos indicus breeds show significantly higher resistance to tick infestation than Bos taurus cattle (Kelly, 1932) and resistant breeds would transmit tick resistance traits to their descendants. However, the selection of resistant animals based on genetic parameters on the basis of repetitive tick counts is difficult and prone to uncontrolled environmental effects (Burrow, 2001; Henshall et al., 2003). Therefore, procedures based on genomics are more objective and hence desirable for identifying tick resistant phenotypes. Hence, attempts have been directed to identify candidate genes and markers associated with resistance against ticks in cattle. Some of the early attempts based on blood protein polymorphisms (Francis and Ashton, 1967) revealed the association of the serum amylase locus with the tick number. Several studies have identified QTLs and SNPs that are associated with host resistance against tick infestation (Gasparin et al., 2007 and Regitano et al., 2008). Later, Machado et al (2010) mapped QTLs on Bos taurus (B. taurus) autosomes which were associated with season- specific resistance against Rhipicephalus microplus (R. microplus) in cattle. Mapholi et al., (2016) also reported several genomic regions having QTLs associated with different tick count traits. Many single nucleotide polymorphism (SNP) in the candidate genes such as epidermal growth factor (EGF) latrophilin and seven transmembrane domain containing-1 (ELTD1) (Porto Neto et al., 2010a), Integrin alpha-11 (ITGA11) (Porto Neto et al., 2010b), Interferon gamma (IFNG) (Maryam et al., 2012) and receptor-interacting serinethreonine kinase 2 (RIPK2) (Porto Neto et al., 2012) were identified having association with resistance against ticks.

Hence, the present study aimed to genotype a population of Vechur and crossbred cattle for SNPs in the QTLs associated with resistance /susceptibility to tick infestation in cattle.

\section{Materials and Methods}

Genotyping and polymorphism study was carried out by PCR-RFLP assay and confirmed by Sanger sequencing. The design of the experiment was approved by the Institutional Animal Ethics Committee of College of Veterinary and Animal Sciences, Pookode (IAEC/COVAS/PKD/13/2019 dated 17-01-19). Native Vechur $(\mathrm{n}=45)$ and crossbred cattle $(n=74)$ of the Kerala Veterinary and Animal Sciences University farms formed the population under study. Blood samples were collected and genomic DNA was isolated using Wizard ${ }^{\circledR}$ Genomic DNA Purification Kit (Promega Cat. No. A1125) as per the kit's protocol. The quality, concentration and purity of DNA were evaluated and the DNA working solution was prepared with a final concentration of $25 \mathrm{ng} / \mu \mathrm{L}$. Four QTLs that were reported to have an association with resistance against ticks in cattle were identified from the Animal QTLdb (https://www. animalgenome.org/cgibin/QTLdb/index) and one SNP from each QTL was used for genotyping and polymorphism study by PCR-RFLP. The SNPs and the QTLs (in parenthesis) used in the study were: rs41661020 (\#101148), rs43708490 (\#135798), rs41577070 (\#135800) and rs29009970 (\#135801). The 
sequences flanking the SNPs were downloaded from dbSNP (https://www.ncbi. nlm. nih.gov /snp/) and Ensemble (https://asia.ensembl.org/ index.html) databases and primers were designed (Table1).

The PCR conditions were optimized for each primer pairs which were then used in the final PCR assays. Each PCR reaction mix of final volume of $25 \mu \mathrm{L}$ prepared in PCR tubes comprised of $12.5 \mu \mathrm{L}$ Emerald Amp GT PCR master mix (Takara Cat. No. RR310A), $1 \mu \mathrm{L}$ forward primer $(10 \mathrm{pmol} / \mu \mathrm{L}), 1 \mu \mathrm{L}$ reverse primer $(10 \mathrm{pmol} / \mu \mathrm{L}), \quad 8.5 \mu \mathrm{L}$ nuclease-free water and $2 \mu \mathrm{L}$ DNA working solution $(25 \mathrm{~nm} / \mu \mathrm{L})$. The amplification conditions were initial denaturation at $94^{\circ} \mathrm{C}$ for $5 \mathrm{~min}$, followed by 30 cycles of denaturation at $94^{\circ} \mathrm{C}$ for 30 seconds; annealing at optimized temperatures (Table 1) for 30 seconds and extension at $72^{\circ} \mathrm{C}$ for 30 seconds. The final extension was done at $72^{\circ} \mathrm{C}$ for $5 \mathrm{~min}$. The amplification was verified by subjecting $2 \mu \mathrm{L}$ PCR product to 2 per cent $(\mathrm{w} / \mathrm{v})$ submarine agarose gel electrophoresis with 100bp DNA ladder (HiMedia, MBT049-50LN) as a marker.

The restriction enzymes (REs)MboII (\#R0148S), AluI (\#R0137S) and HpyCH4IV (\#R0619S) of New England Bio labs were used for the digestion of the PCR products as per the manufacturer's protocol. A digestion reaction mix prepared in PCR tubes contained $2.5 \mu \mathrm{L}$ of $10 \times \mathrm{RE}$ buffer, one unit of restriction enzyme and approximately $22.3 \mu \mathrm{L}$ of the PCR product. The digestion reaction mix was incubated overnight (14 to $16 \mathrm{~h}$ ) at the optimum temperature prescribed by the manufacturer. Next, enzymes were deactivated at the required temperature in a water bath. The digestion products were subjected to 2.5 per cent (w/v) submarine horizontal agarose (low EEO) gel electrophoresis at $125 \mathrm{~V}$ for $3 \mathrm{~h}$ with $50 \mathrm{bp}$ marker (HiMedia Cat. No: MBT084-50LN). The fragmentation pattern for each SNP was documented with gel documentation system. Details of the cattle SNPs, REs and expected fragment sizes are listed in Table 2.

For confirming the genotypes and polymorphisms, the PCR products were sent to $\mathrm{M} / \mathrm{S}$ AgriGenom Lab Private Limited, Cochin, India for sequencing by Sanger dideoxy chain termination method. The sequence data were analyzed by FinchTV 1.4 .0

(https://digitalworldbiology.com/FinchTV). The number of individuals belonging to different genotypes were recorded by direct counting (Falconer and Mackay, 1996). The allele and genotype frequencies were estimated by POPGENE 1.32 (https://sites.ualberta.ca/ fyeh/index.html).

The Chi-square test was used to test whether the population was in Hardy-Weinberg equilibrium (HWE).

\section{Results and Discussion}

The genotypes and allele frequencies of the SNPs in the population under study are given in the tables 3 to 6 . The PCR-RFLP results were confirmed by sequencing (Fig. 1 to 4 ).

In brief, the PCR-RFLP revealed a polymorphic pattern for the SNP rs41577070 in the cattle population under study, whereas, only two genotypes were seen for the SNPs rs41661020 and rs43708490. However, for the SNP rs29009970, the PCR-RFLP revealed only GC genotype in the crossbred population and GG and GC genotypes in the Vechur population.

The results of the Chi-square test are shown in the tables 7 to 10 . By comparing the observed and expected frequencies, it was found that cattle population under study was in HWE in the case of SNP rs41577070, 
rs41661020 and rs43708490. However, both the Vechur and crossbred populations were

departed from HWE significantly $(\mathrm{p} \leq 0.01)$ for SNP rs29009970 (Table 9).

Table.1 Oligonucleotide primers with optimized annealing temperatures for the primer pairs used in the study

\begin{tabular}{|c|c|c|c|}
\hline Cattle SNP ID & Primer Name & Sequence (5' to $\left.3^{\prime}\right)$ & $\operatorname{Ta}\left({ }^{\circ} \mathrm{C}\right)$ \\
\hline \multirow[t]{2}{*}{ rs41577070 } & TR-2N-F & GCTGAGCCTTGCAAGAACAT & \multirow[t]{2}{*}{$60.8^{\circ} \mathrm{C}$} \\
\hline & TR-2N-R & AGGAGGGTCACAAGGAGTCA & \\
\hline \multirow[t]{2}{*}{ rs41661020 } & TR-3-F & GGACTGAGAAAATAGTAGCC & \multirow[t]{2}{*}{$54.0^{\circ} \mathrm{C}$} \\
\hline & TR-3-R & ТСТТТТССТАСААССТСС & \\
\hline \multirow[t]{2}{*}{ rs29009970 } & TR-4-F & GTATGTGGTTTTAGGTAGG & \multirow[t]{2}{*}{$54.0^{\circ} \mathrm{C}$} \\
\hline & TR-4-R & CAAACACACACAAAACGC & \\
\hline \multirow[t]{2}{*}{ rs43708490 } & TR-5-F & CCTCAGGTTCCTACTGATG & \multirow[t]{2}{*}{$53.0^{\circ} \mathrm{C}$} \\
\hline & TR-5-R & AGGGTCATGTTTTCCATC & \\
\hline
\end{tabular}

Table.2 Details of cattle SNPs, allele, restriction enzymes used and expected fragmentation patterns

\begin{tabular}{|l|l|l|c|c|c|}
\hline Cattle SNP ID & SNP allele & \multicolumn{1}{|c|}{ REs } & \multicolumn{3}{|c|}{$\begin{array}{c}\text { Fragmentation pattern } \\
\text { (approx. size in bp) }\end{array}$} \\
\cline { 3 - 7 } & & & AA & BB \\
\hline rs41577070 & A/G & MboII & 118,174 & $118,174,292$ & 292 \\
\hline rs41661020 & T/C & AluI & 238 & $96,142,238$ & 96,142 \\
\hline rs29009970 & C/G & HpyCH4IV & 281 & $98,183,281$ & 183,98 \\
\hline rs43708490 & A/G & HpyCH4IV & 276 & $98,178,276$ & 98,178 \\
\hline
\end{tabular}

Table.3 Genotype and allele frequencies of SNP rs41577070 in Vechur and crossbred cattle

\begin{tabular}{|c|c|c|c|c|c|}
\hline \multirow{2}{*}{ Population } & \multicolumn{3}{|c|}{ Genotype frequency } & \multicolumn{2}{c|}{ Allele frequency } \\
\cline { 2 - 6 } & AA & AG & GG & A & G \\
\hline Crossbred (74) & $0.32(24)$ & $0.53(39)$ & $0.15(11)$ & 0.59 & $\mathbf{0 . 4 1}$ \\
\hline Vechur (45) & $0.33(15)$ & $0.49(22)$ & $0.18(8)$ & 0.58 & $\mathbf{0 . 4 2}$ \\
\hline Pooled population (119) & $\mathbf{0 . 3 3}(\mathbf{3 9})$ & $\mathbf{0 . 5 1}(\mathbf{6 1 )}$ & $\mathbf{0 . 1 6}(\mathbf{1 9})$ & $\mathbf{0 . 5 8}$ & $\mathbf{0 . 4 2}$ \\
\hline
\end{tabular}

Figures in parenthesis are actual numbers

Table.4 Genotype and allele frequencies of SNP rs41661020 in Vechur and crossbred cattle

\begin{tabular}{|c|c|c|c|c|c|}
\hline \multirow{2}{*}{ Population } & \multicolumn{3}{|c|}{ Genotype frequency } & \multicolumn{2}{c|}{ Allele frequency } \\
\cline { 2 - 6 } & TT & TC & CC & T & C \\
\hline Crossbred (74) & $0.65(48)$ & $0.35(26)$ & 0.0 & 0.83 & $\mathbf{0 . 1 7}$ \\
\hline Vechur (45) & $0.73(33)$ & $0.27(12)$ & 0.0 & 0.87 & $\mathbf{0 . 1 3}$ \\
\hline Pooled population (119) & $\mathbf{0 . 6 8}(\mathbf{8 1})$ & $\mathbf{0 . 3 2}(\mathbf{3 8})$ & $\mathbf{0 . 0}$ & $\mathbf{0 . 8 4}$ & $\mathbf{0 . 1 6}$ \\
\hline
\end{tabular}

Figures in parenthesis are actual numbers 
Table.5 Genotype and allele frequencies of SNP rs29009970 in Vechur and crossbred cattle

\begin{tabular}{|l|c|c|c|c|c|}
\hline \multicolumn{1}{|c|}{ Population } & \multicolumn{3}{|c|}{ Genotype frequency } & \multicolumn{2}{c|}{ Allele frequency } \\
\hline & GG & CG & CC & G & C \\
\hline Crossbred (74) & 0.0 & $1.0(74)$ & 0.0 & 0.5 & $\mathbf{0 . 5}$ \\
\hline Vechur (45) & $0.07(3)$ & $0.93(42)$ & 0.0 & 0.53 & $\mathbf{0 . 4 7}$ \\
\hline Pooled population (119) & $\mathbf{0 . 0 3 ( 3 )}$ & $\mathbf{0 . 9 7 ( 1 1 6 )}$ & $\mathbf{0 . 0}$ & $\mathbf{0 . 5 1}$ & $\mathbf{0 . 4 9}$ \\
\hline
\end{tabular}

Figures in parenthesis are actual numbers

Table.6 Genotype and allele frequencies of SNP rs43708490 in Vechur and crossbred cattle

\begin{tabular}{|l|c|c|c|c|c|}
\hline \multicolumn{1}{|c|}{ Population } & \multicolumn{3}{|c|}{ Genotype frequency } & \multicolumn{2}{c|}{ Allele frequency } \\
\hline & AA & AG & GG & A & G \\
\hline Crossbred (74) & $0.96(71)$ & $0.04(3)$ & 0.0 & 0.98 & $\mathbf{0 . 0 2}$ \\
\hline Vechur (45) & $0.96(43)$ & $0.04(2)$ & 0.0 & 0.98 & $\mathbf{0 . 0 2}$ \\
\hline Pooled population (119) & $\mathbf{0 . 9 6 ( 1 1 4 )}$ & $\mathbf{0 . 0 4}(\mathbf{5})$ & $\mathbf{0 . 0}$ & $\mathbf{0 . 9 8}$ & $\mathbf{0 . 0 2}$ \\
\hline
\end{tabular}

Figures in parenthesis are actual numbers

Table.7 Testing of genotypes of SNP rs41577070 for HWE in Vechur and crossbred cattle

\begin{tabular}{|c|c|c|c|c|c|}
\hline \multirow[t]{2}{*}{ Population } & \multirow[t]{2}{*}{ Source } & \multicolumn{3}{|c|}{ Genotypes } & \multirow[t]{2}{*}{$\chi^{2}$ value $(\mathrm{df}=1)$} \\
\hline & & $\mathbf{A A}$ & $\mathbf{A G}$ & GG & \\
\hline \multirow{2}{*}{ Crossbred } & Observed & 24.0 & 39.0 & 11.0 & \multirow{2}{*}{$0.48^{\mathrm{ns}}$} \\
\hline & Expected & 25.45 & 36.10 & 12.45 & \\
\hline \multirow[t]{2}{*}{ Vechur } & Observed & 15.0 & 22.0 & 8.0 & \multirow[t]{2}{*}{$0.003^{\mathrm{ns}}$} \\
\hline & Expected & 14.90 & 22.20 & 7.89 & \\
\hline \multirow{2}{*}{$\begin{array}{c}\text { Pooled } \\
\text { population }\end{array}$} & Observed & 39.0 & 61.0 & 19.0 & \multirow[t]{2}{*}{$0.31^{\mathrm{ns}}$} \\
\hline & Expected & 40.47 & 58.06 & 20.47 & \\
\hline
\end{tabular}

ns - Non- Significant at 5\% level

$\mathrm{df}$ - degrees of freedom

Table.8 Testing of genotypes of SNP rs41661020 for HWE in Vechur and crossbred cattle

\begin{tabular}{|c|c|c|c|c|c|}
\hline \multirow[t]{2}{*}{ Population } & \multirow[t]{2}{*}{ Source } & \multicolumn{3}{|c|}{ Genotypes } & \multirow[t]{2}{*}{$\chi^{2}$ value $(\mathrm{df}=1)$} \\
\hline & & TT & TC & $\mathrm{CC}$ & \\
\hline \multirow[t]{2}{*}{ Crossbred } & Observed & 48.0 & 26.0 & 0.0 & \multirow[t]{2}{*}{$3.21^{\mathrm{ns}}$} \\
\hline & Expected & 50.21 & 21.58 & 2.21 & \\
\hline \multirow[t]{2}{*}{ Vechur } & Observed & 33.0 & 12.0 & 0.0 & \multirow[t]{2}{*}{$0.97^{\text {ns }}$} \\
\hline & Expected & 33.74 & 10.52 & 0.74 & \\
\hline \multirow{2}{*}{$\begin{array}{c}\text { Pooled } \\
\text { Population }\end{array}$} & Observed & 81.0 & 38.0 & 0.0 & \multirow[t]{2}{*}{$4.17^{\mathrm{ns}}$} \\
\hline & Expected & 83.97 & 32.06 & 2.97 & \\
\hline
\end{tabular}

ns- Non- Significant at $5 \%$ level

df - degrees of freedom 
Table.9 Testing of genotypes of SNP rs29009970 for HWE in Vechur and crossbred cattle

\begin{tabular}{|c|c|c|c|c|c|}
\hline \multirow{2}{*}{ Population } & Source & \multicolumn{3}{|c|}{ Genotypes } & \multirow{2}{*}{$\chi^{\mathbf{2}}$ value $(\mathbf{d f}=\mathbf{1})$} \\
\cline { 3 - 6 } & & GG & GC & CC & \\
\hline \multirow{2}{*}{ Crossbred } & Observed & 0.0 & 74.0 & 0.0 & \multirow{2}{*}{$\mathbf{7 3 . 0 0}^{*} *$} \\
\cline { 2 - 5 } & Expected & 18.37 & 37.25 & 18.37 & \\
\hline \multirow{2}{*}{ Vechur } & Observed & 3.0 & 42.0 & 0.0 & \multirow{3}{*}{$33.59 * *$} \\
\cline { 2 - 5 } Pooled & Expected & 12.67 & 22.65 & 9.67 & \\
\hline Population & Observed & 3.0 & 116.0 & 0.0 & $\mathbf{1 0 6 . 6 3} * *$ \\
\hline
\end{tabular}

** - Significant at $1 \%$ level

df - degrees of freedom

Table.10 Testing of genotypes of SNP rs43708490 for HWE in Vechur and crossbred cattle

\begin{tabular}{|c|c|c|c|c|c|}
\hline \multirow{2}{*}{ Population } & Source & \multicolumn{3}{|c|}{ Genotypes } & \multirow{2}{*}{$\boldsymbol{\chi}^{\mathbf{2}}$ value (df=1) } \\
\cline { 3 - 6 } & & AA & AG & GG & \\
\hline \multirow{2}{*}{ Crossbred } & Observed & 71.0 & 3.0 & 0.0 & $\mathbf{0 . 0 2}^{\text {ns }}$ \\
\cline { 2 - 6 } & Expected & 71.02 & 2.96 & 0.0 & \\
\hline \multirow{2}{*}{ Vechur } & Observed & 43.0 & 2.0 & 0.0 & $\mathbf{0 . 0 1}^{\text {ns }}$ \\
\cline { 2 - 6 } & Expected & 43.01 & 1.98 & 0.01 & \\
\hline \multirow{2}{*}{$\begin{array}{c}\text { Pooled } \\
\text { population }\end{array}$} & Observed & 114.0 & 5.0 & 0.0 & $\mathbf{0 . 0 4}^{\text {ns }}$ \\
\hline
\end{tabular}

Ns- Non-significant at $5 \%$ level $\mathrm{df}$ - degrees of freedom

Fig.1 Study of genetic polymorphism at SNP rs41577070 of QTL \#135800. Representative photographs of PCR-RFLP results. This locus was polymorphic in the population studied. Sample numbers are given on the top of the gel and fragment sizes are shown on the right side. M: Himedia 50bp DNA ladder marker, 2.5\% agarose gel, $125 \mathrm{~V}$ for $3 \mathrm{hrs}$ (A). Chromatogram confirming the AG genotype (B), GG genotype (C) and AA genotype (D)

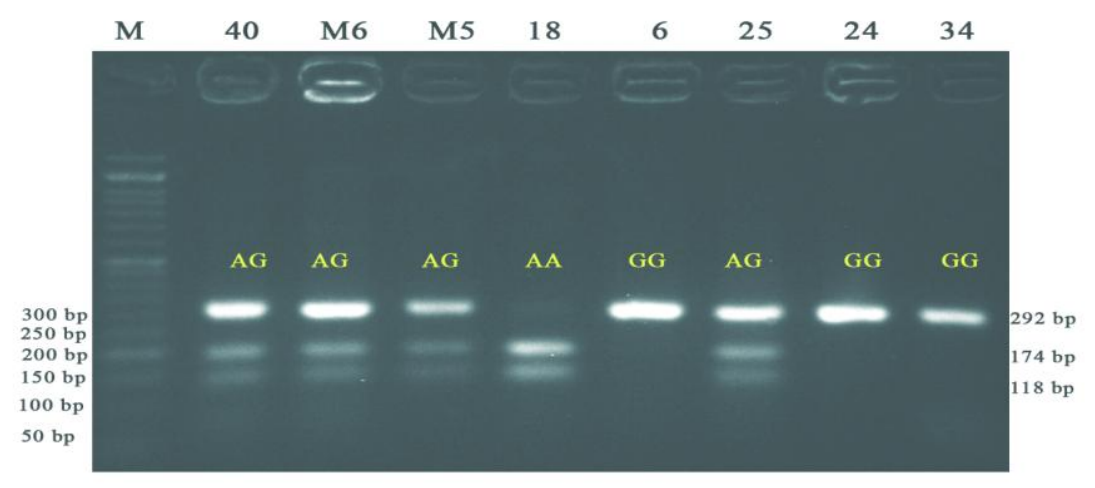

(A) 


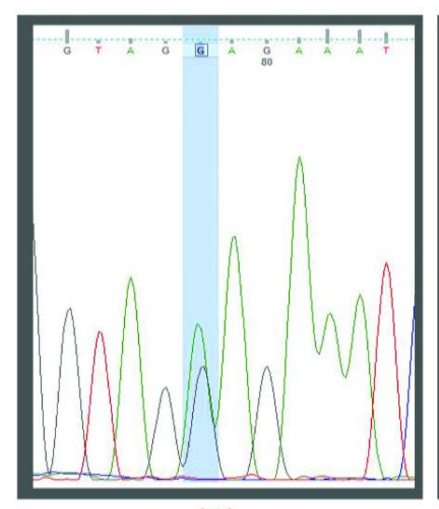

(B)

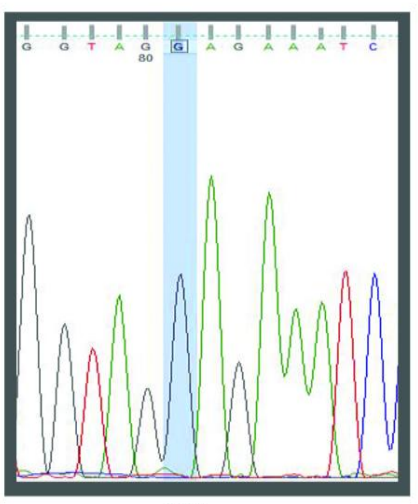

(C)

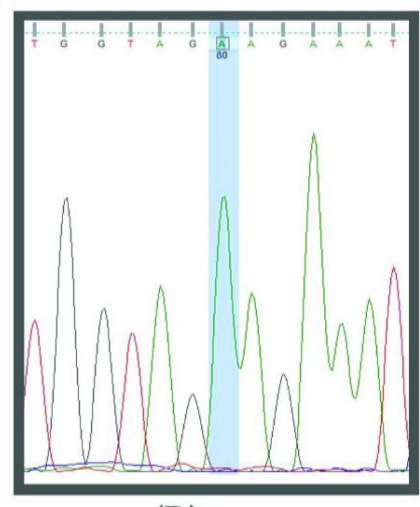

(D)

Fig.2 Study of genetic polymorphism at SNP rs41661020 of QTL 101148. Representative photographs of PCR-RFLP results. This locus was polymorphic in the population studied. Sample numbers are given on the top of the gel and fragment sizes are shown on the right side. M: Himedia 50bp DNA ladder marker, 2.5\% agarose gel, $125 \mathrm{~V}$ for $3 \mathrm{hrs}$ (A). Chromatogram confirming the TC genotype (B) andTT genotype (C)

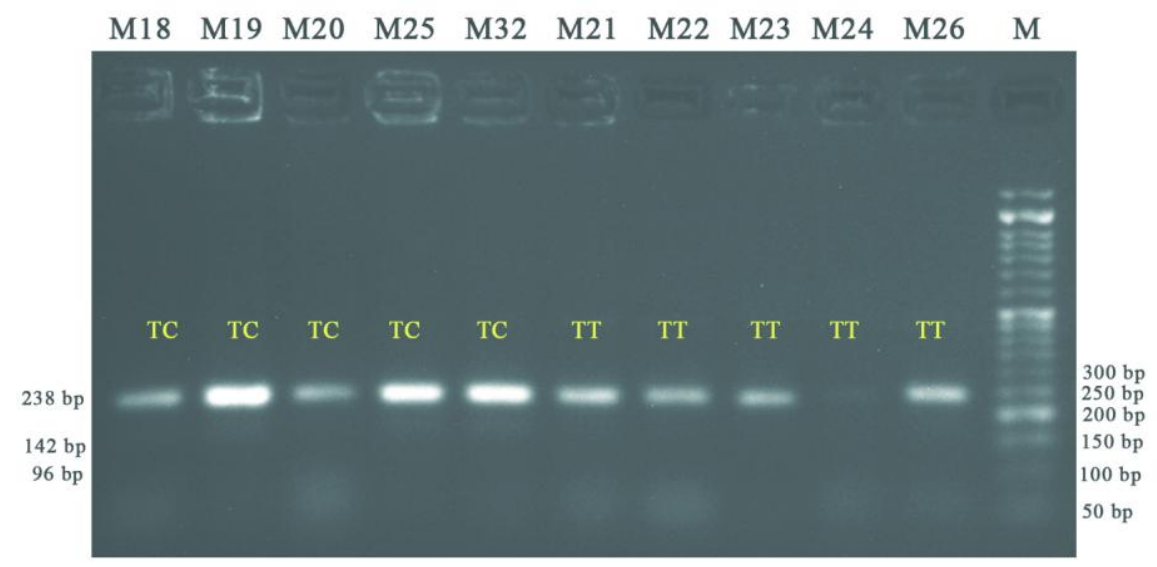

(A)

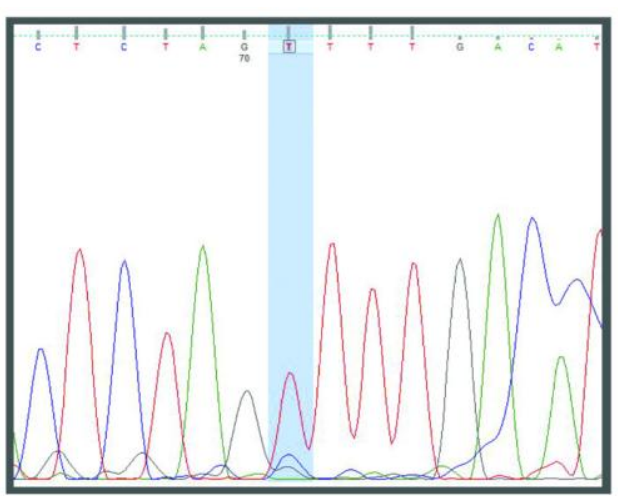

(B)

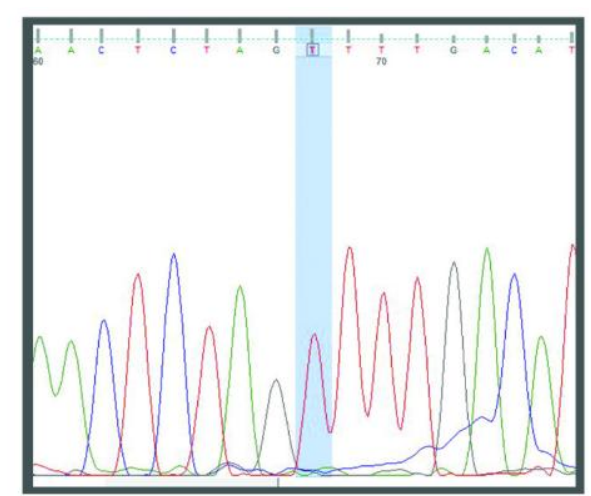

(C) 
Fig.3 Study of genetic polymorphism at SNP rs29009970 of QTL 135801. Representative photographs of PCR-RFLP results. This locus was polymorphic in the population studied.

Sample numbers are given on the top of the gel and fragment sizes are shown on the right side. M: Himedia 50bp DNA ladder marker, 2.5\% agarose gel, $125 \mathrm{~V}$ for $3 \mathrm{hrs}$ (A). Chromatogram confirming the GC genotype (B) andGG genotype (C)
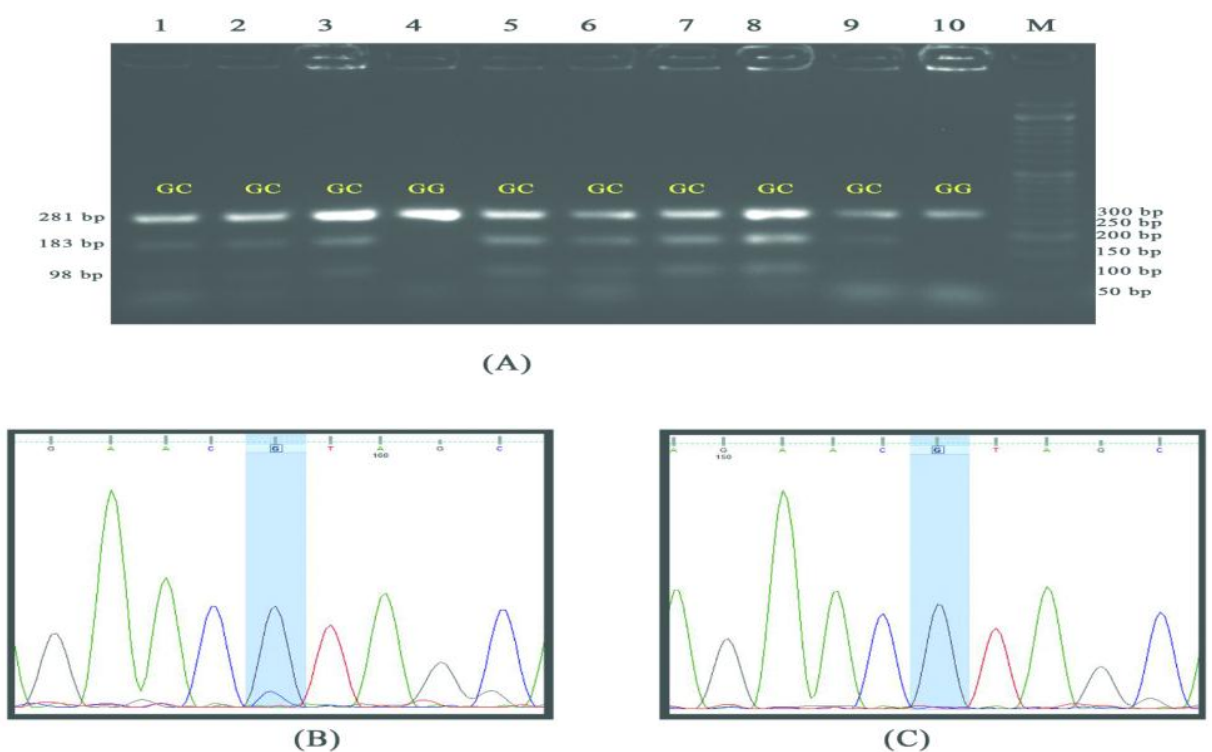

Fig.4 Study of genetic polymorphism at SNP rs43708490 of QTL 135798. Representative photographs of PCR-RFLP results. This locus was polymorphic in the population studied. Sample numbers are given on the top of the gel and fragment sizes are shown on the right side. M: Himedia 50bp DNA ladder marker, 2.5\% agarose gel, $125 \mathrm{~V}$ for 3 hrs (A). Chromatogram confirming the AG genotype (B) and AA genotype (C)

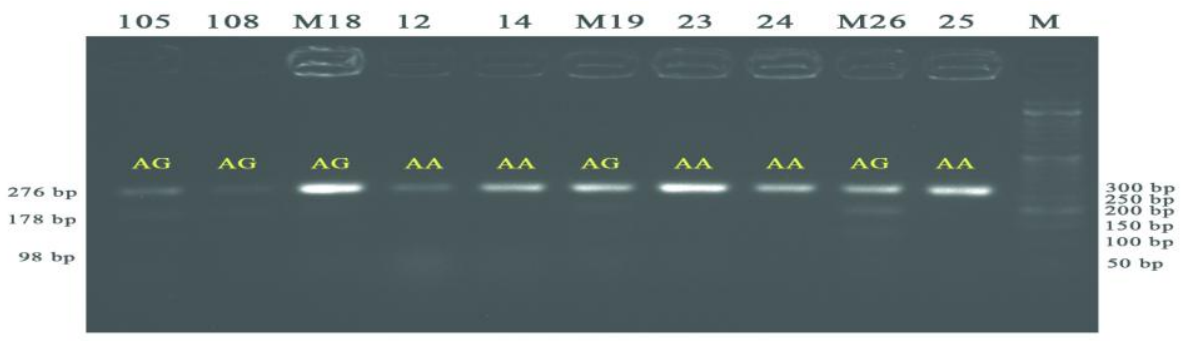

(A)

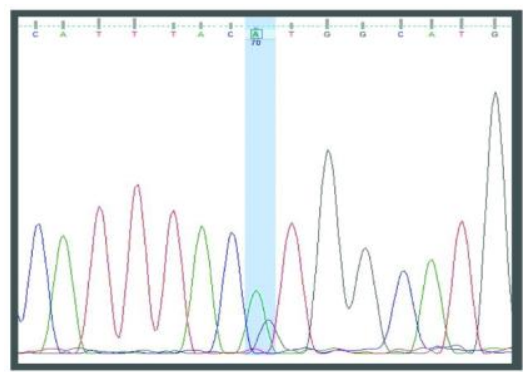

(B)

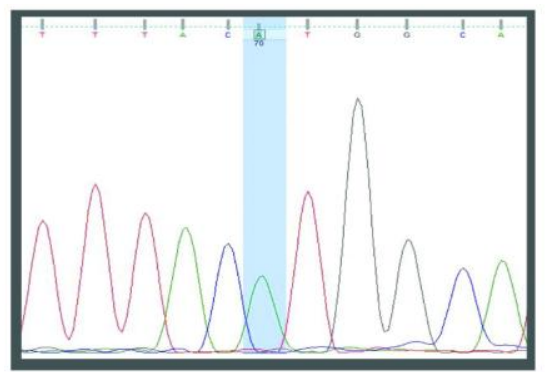

(C) 
Several factors may be responsible for the deviation of polymorphic loci from the HWE such as small population size, presence of null alleles, Wahlund effect, genetic drift, nonrandom mating, mutation, migration and selective forces operating at certain loci (Falconer and Mackay, 1996; Phyu et al., 2017). For SNP rs29009970, only CG heterozygote was present in the crossbreds. In the Vechur cattle, 93 per cent of the animals were CG genotypes. Therefore, it could be inferred that there might be some selective advantage for the $\mathrm{CG}$ heterozygotes in the cattle population under study.

\section{Acknowledgments}

We sincerely thank the Kerala Veterinary and Animal Sciences University and the Kerala State Council for Science, Technology and Environment for funding and facilities provided to us for conducting this research work.

\section{References}

Burrow, H.M. 2001. Variances and covariances between productive and adaptive traits and temperament in a composite breed of tropical beef cattle. Livest. Prod. Sci. 70: 213-233.

Castro-Janer, E., Martins, J.R., Mendes, M.C., Namindome, A., Klafke, G.M. and Schumaker, T.T.S. 2010. Diagnoses of fipronil resistance in Brazilian cattle ticks (Rhipicephalus (Boophilus) microplus) using in vitro larval bioassays. Vet. Parasitol.173: 300-306.

Falconer, D.S. and Mackay, T.F.C. 1996. Introduction to Quantitative Genetics, fourth ed. Longmans Green, Essex., $464 \mathrm{p}$.

Food and Agriculture Organization.1984. Food and Agriculture Organization [FAO] Statistics. United Nations. Available: http://faostat.fao.org/.
Mar.1985].

Francis, J. and Ashton, G.C. 1967. Tick resistance in cattle: its stability and correlation with various genetic characteristics. Aust. J. Exp. Biol. Med. Sci. 45: 131-140.

Gasparin, G., Miyata, M.L.L., Coutinho, L.L., Martinez, M.L., Teodoro, R.L., Furlong,J., Machado, M.A., Silva, M.V.G.B., Sonstegard, T.S. and Regitano, L.C.A. 2007. Mapping of quantitative trait loci controlling tick (Rhipicephalus (Boophilus) microplus) resistance on bovine chromosomes 5, 7 and 14. Anim. Genet. 38: 453-459.

Ghosh, S., Bansal, G.C., Gupta, S.C., Ray, D., Khan, M.Q., Irshad, H., Shahiduzzaman, M.D., Seitzer, U. and Ahmed, J.S. 2007. Status of tick distribution in Bangladesh, India and Pakistan. Parasitol. Res. 101: 207-216.

Henshall, J., Prayaga, K.C. and Burrow, H.M. Covariance structures for modeling repeated tick counts in beef cattle. In: Proceeding of Vth Conference of Association for the Advancement of Animal Breeding and Genetics; 2003, Rockhampton. Cooperative Research Centre for Cattle and Beef Quality (CSIRO), Livestock Industries. pp. 119122

Kelley, R. B. 1932. Zebu (Brahman) crosses cattle and their possibilities in north Australia. Pamph. Coun. Scient. Ind. Res. Aust. No. 27.

Lew-Tabor, A.E. and Valle, M.R. 2016. A review of reverse vaccinology approaches for the development of vaccines against ticks and tick borne diseases. Ticks Tick Borne Dis.7: 573585.

Li, A.Y., Davey, R.B., Miller, R.J. and George, J.E. 2005. Mode of inheritance of amitraz resistance in a Brazilian strain of the southern cattle tick, Boophilus microplus (Acari: 
Ixodidae). Exp. Appl. Acarology.37: $183-188$.

Machado, M.A., Azevedo, A.L.S., Teodoro, R.L., Pires, M.A., Peixoto, M.G.C.D., de Freitas, C., Prata, M.C.A., Furlong, J., da Silva, M.V.G.B., Guimarães, S.E.F., Regitano, L.C.A., Coutinho, L.L., Gasparin, G. and Verneque, R.S. 2010. Genome wide scan for quantitative trait loci affecting tick resistance in cattle (Bos taurus x Bos indicus). BMC Genomics. 11: 280-291.

Mapholi, N.O., Maiwashe, A., Matika, O., Riggio, V., Bishop, S.C., MacNeil, M.D., Banga, C., Taylor, J.F. and Dzama, K. 2016. Genome-wide association study of tick resistance in South African Nguni cattle. Ticks Tick Borne Dis. 7: 487-497.

Maryam, J., Babar, M.E., Nadeem, A. and Hussain, T. 2012. Genetic variants in interferon gamma (IFN- $\gamma)$ gene are associated with resistance against ticks in Bos taurus and Bos indicus. Mol. Biol. Rep. 39: 4565-4570.

Minjauw, B. and McLeod, A. 2003. Tickborne diseases and poverty: the impact of ticks and tick-borne diseases on the livelihoods of small-scale and marginal livestock owners in India and eastern and southern Africa. Research Report, DFID Animal Health Programme, Centre for Tropical Veterinary Medicine, University of Edinburgh, UK.
Phyu, P.P., Pichler, R., Soe, O., Aung, P.P., Than, M., Shamsuddhin, M., Diallo, A. and Periasamy, K. 2017. Genetic diversity, population structure and phylogeography of Myanmar goats. Small Ruminant Res.148: 33- 42.

Porto Neto, L. R., Bunch, R. J., Harrison, B. E. and Barendse, W. 2010a. DNA variation in the gene ELTD1 is associated with tick burden in cattle. Anim. Genet. 42: 50-55.

Porto Neto, L. R., Bunch, R.J., Harrison, B. E., Prayaga, K.C. and Barendse, W. 2010b. Haplotypes that include the integrin alpha 11 gene are associated with tick burden in cattle. BMC Genet. 11: 55.

Porto Neto, L.R., Jonsson, N.N., Ingham, A., Bunch, R.J., Harrison, B.E. and Barendse, W. 2012. The RIPK2 gene: a positional candidate for tick burden supported by genetic associations in cattle and immunological response of knockout mouse. Immunogenetics. 64: 379-388.

Regitano, L.C.A., Ibelli, A.M.G., Gasparin, G., Miyata, M., Azevedo, A.L.S., Coutinho, L.L., Teodoro, R.L., Machado, M.A., Silva, M.V.G.B., Nakata, L.C., Zaros, L.G., Sonstegard, T.S., Silva, A.M., Alencar, M.M. and Oliveira, M.C.S. 2008. On the search for markers of tick resistance in bovines. Dev. Biol. 132: 225-230.

\section{How to cite this article:}

Bhagyashree Kamble Mukhund, C. N. Dinesh, P. M. Rojan, Reghu Ravindran, K. A. Bindu, V. N. Muhasin Asaf, P. R. Sreeshma and Deepna, T. 2020. Analysis of Single Nucleotide Polymorphisms in the QTLS Associated with Tick Resistance/Susceptibility in the Native Vechur and Cross red Cattle of Kerala State. Int.J.Curr.Microbiol.App.Sci. 9(09): 3078-3087. doi: https://doi.org/10.20546/ijcmas.2020.909.380 